\title{
New GMC guidance takes a major, ethically flawed, backward step
}

\author{
lan Roberts co-director, clinical trials unit, and professor of epidemiology ${ }^{1}$, Brigitte Chaudhry founder ${ }^{2}$, \\ lain Chalmers coordinator ${ }^{3}$
}

${ }^{1}$ London School of Hygiene and Tropical Medicine, London WC1E 7HT, UK; ${ }^{2}$ RoadPeace, UK; ${ }^{3}$ James Lind Initiative, Oxford, UK

Doctors and patients have good reason not to be enamoured with new General Medical Council (GMC) guidance. ${ }^{1}$ Whereas the 2006 edition of Good Medical Practice stated that doctors "must work with colleagues and patients ... to help resolve uncertainties about the effects of treatments" (para 14f), ${ }^{2}$ this principle and the relevant paragraph have been jettisoned from the recently published 2013 edition. This is all the more perverse because the statement has often been referred to approvingly in articles, presentations, and books written for the public, and readers of the GMC's guidance on research are referred to it. This major, ethically flawed, backward step ignores the fact that patients have suffered and died unnecessarily because doctors failed to confront uncertainties about the effects of treatments and to support the research needed to reduce these..$^{3-5}$

According to the GMC, good doctors must provide clinical care only when they are satisfied that the drugs or treatments offered are likely to serve patients' needs and are based on the best available evidence (paras 16a, b). We challenge the moral basis of the GMC's injunction to use research evidence without an accompanying injunction to contribute to its production. Without a responsibility to contribute to the production of new knowledge this obligation implies a parasitic dependence on the work of unspecified others. In thankful contrast, the NHS makes clear its commitment to research and has made innovation and research a priority. ${ }^{6}$

The new edition of the GMC's principal guidance to doctors is a threat to the best interests of patients. It should be withdrawn and reissued after appropriate amendment.

ian.roberts@lshtm.ac.uk

Competing interests: None declared.

Full response at: www.bmj.com/content/346/bmj.f2626/rr/649454.

Jaques H. GMC launches new guidance for patients on what to expect from their doctor. BMJ 2013;346:f2626. (23 April.)

2 General Medical Council. Good medical practice. 2006.

3 Ker K, Perel P, Blackhall K, Roberts I. How effective are some common treatments for traumatic brain injury? BMJ 2008;337:a865.

4 CRASH Trial Collaborators. Effect of intravenous corticosteroids on death within 14 days in 10008 adults with clinically significant head injury (MRC CRASH Trial): a randomised placebo-controlled trial. Lancet 2004;364:1321-8.

5 Shakur H, Roberts I, Bautista R, Caballero J, Coats T, Dewan Y, et al; CRASH-2 trial collaborators. Effects of tranexamic acid on death, vascular occlusive events, and blood transfusion in trauma patients with significant haemorrhage (CRASH-2): a randomised, placebo-controlled trial. Lancet 2010;376:23-32.

6 Department of Health. Best research for best health: a new national health research strategy. The NHS contribution to health research in England. 2006. https://www.gov.uk/ government/uploads/system/uploads/attachment_data/file/136578/dh_4127152.pdf.

Cite this as: BMJ 2013;346:f3879

๑๑ BMJ Publishing Group Ltd 2013 